\title{
Co-Designing Innovative Practice-Based Education for Speech Pathology Students
}

\author{
*Steven J. Kamper ${ }^{a b}$, Amabile B. Dario ${ }^{a}$, Melina Waibel $^{b}$, David O'Connor ${ }^{b}$, \& \\ Elizabeth Bourne ${ }^{a}$ \\ a: School of Health Sciences, University of Sydney, Australia; b: Nepean Blue Mountains Local \\ Heath District, Australia
}

\section{The impact of COVID-19 on clinical education}

The COVID-19 pandemic had profound and wide-ranging impacts on healthcare in 2020. Although attention focussed on screening and acute care provision, the pandemic also affected clinical education of health professionals. Impacts were driven by the need to rapidly adapt services to minimise virus transmission risk (Australian Department of Health, 2020). This involved redeployment of staff involved in clinical education and policies to reduce extra-numerary personnel in clinical areas.

In 2020, more than half of the planned clinical education placements for Speech Pathology students enrolled at University of Sydney, Australia were paused or cancelled. Across New South Wales Health, cancellations occurred as administrative and clinical staff had to adapt care provision to meet physical distancing, hygiene and re-prioritisation requirements. This reduced opportunities for student supervision and education. Cancellation of placements had implications for on-time completion of professional training with attendant stress, costs and workload reorganisation for students and the University. The broad-scale impact of COVID-19 across Australia means that such delays in health professional training may have implications for ongoing workforce preparation. In this article we reflect on the development and piloting of a new clinical education model that involves telehealth services and tele-supervision of Speech Pathology students in Sydney, Australia.

\section{An innovative clinical education model}

Nepean Blue Mountains Local Health District is a state government health provider that serves a population of approximately 400,000 people on the western edge of Sydney, Australia (Nepean Blue Mountains Local Health District, 2017). Outpatient speech pathology services are directed from the main teaching hospital in the district, Nepean Hospital. To maintain continuity of services alongside efforts to reduce COVID virus transmission, the outpatient Speech Pathology department at Nepean Hospital sought to rapidly expand telehealth services. This involved establishing patient eligibility criteria for telehealth (reliable internet connection, appropriate devices, support people, sufficient cognition,

*Corresponding Author: Professor Steven J. Kamper, School of Health Sciences, University of Sydney. Rm. 1.05, 62, Derby St. Kingswood. NSW 2747 Australia.

Journal URL: https://publications.coventry.ac.uk/index.php/pblh

Kamper, S.J., Dario, A.B., Waibel, M., O’Connor, D., \& Bourne, E. (2021). Co-designing innovative practice-based education for speech pathology students. International Journal of Practice-based Learning in Health and Social Care, 9(2), 74-77. DOI 10.18552/ijpblhsc.v9i2.746

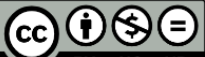

BY NC ND (C) 2021 Kamper, S.J., Dario, A.B., Waibel, M., O’Connor, D., \& Bourne, E. This Open Access article is distributed under the terms of the Creative Commons Attribution Attribution-Non-Commercial No Derivatives 4.0 International License (https://creativecommons.org/licenses/by-nc-nd/4.0/), which permits unrestricted non-commercial use, distribution, and reproduction in any medium, provided the original work is properly cited and is unaltered. 
willingness), upgrading technology, designing technical solutions that enabled interconnectivity, digitising assessment and therapy resources, videos, presentations, websites, and developing a patient feedback questionnaire.

While establishing new services involved substantial additional work for managers, administration and clinicians, it also created an opportunity. A telehealth clinical education placement model was codeveloped by Nepean Hospital speech pathology department, and the Work Integrated Learning (WIL) unit in School of Health Sciences, University of Sydney. The WIL unit is an interprofessional team responsible for organising education in workplace contexts. The team supports students and clinical educators to deliver high quality authentic learning. Development of the model involved consultation between the Department Head of Speech Pathology, the clinical educator and WIL academics. The starting point for discussions was the description of the new telehealth services to be implemented by the department in response to COVID. From here opportunities for student involvement were identified by Speech Pathology staff and explored, with WIL academics detailing whether and to what extent these opportunities met the requirements for clinical education placements. This model represents a departure from a traditional one where the needs of the university are the priority for placement design.

The goal of the placement model was to create mutually beneficial outcomes (Nisbet et al., 2020). This placement model enabled the speech pathology department to benefit from additional capacity provided by students, students benefitted through exposure to delivering care in a dynamic environment and patients benefitted via access to best practice care during the pandemic. During 3-6 week blocks, pairs of students provided telehealth services with support from their clinical educator and peer via telesupervision. This experience was alongside on-site, face-to face service delivery. While some speech pathology services have used telehealth previously (Rietdijk et al., 2020a; Rietdijk et al., 2020b) and there have been some trials of tele-supervision in speech pathology (Chipchase et al., 2014; Nagarajan et al., 2016), this model uniquely integrated these in one placement.

\section{Reflections}

\section{Positives}

Co-development of the new model meant that high quality, practice-based learning opportunities were available for students during a time of upheaval in the healthcare system. Because most clinical education units for Speech Pathology students are in their final year, cancellations put on-time completion at risk for many students. This new model helped enable completion of training and subsequent entry into the workforce for University of Sydney Speech Pathology students. While the number of students that participated in this pilot program at one facility was small (4 students), the process of co-development and the model itself serve as exemplars. The University of Sydney plans to extend and adapt the model for implementation in other health districts going forward. The example demonstrates the potential for institutional partnerships to rapidly solve problems via co-production to the mutual benefit of health services, universities and students.

Speech Pathology students gained experience delivering telehealth services within a hospital service context that was seldom previously available. The COVID-19 pandemic increased the rate of a shift in healthcare towards remote delivery, including telehealth. While the rate of expansion of telehealth services has varied across jurisdictions and professions, it is practically certain that Speech Pathologists will soon require skills and expertise in telehealth beyond that of current practitioners. The clinical education model created the opportunity to expose student Speech Pathologists to telehealth and further, for the university and health district to develop structured training to meet the needs of the future workforce.

Student feedback from the clinical education units was excellent. Feedback was collected via a validated measure of student clinical education experience (McAllister et al., 2018). Of note, students rated the telehealth unit higher than other speech pathology clinical education blocks regarding; learning environment, fit between placement site and learning needs, and quality of supervision. This shows that students appreciate the need for training in new care delivery methods and speaks to the buy-in and commitment of clinical educators from Nepean Blue Mountains Speech Pathology department. 
The Speech Pathology department and university were able to support a part-time clinician to become a clinical educator. This was enabled by integrating student peer learning and complementary learning experiences and reducing the number of days the students attended the hospital onsite. Clinical educator roles are critical to ensure the high-quality education of health professionals, helping to align professional practice and education, and provide diversity in career options for clinicians.

Participation of students in delivering telehealth provided additional capacity to the department. This additional capacity was of particular value during increased workload due to the impacts of COVID-19. Further, given the new procedures and skills needed during this time, clinical staff had the opportunity to learn alongside students in telehealth design and delivery.

Speech Pathology clinicians, management and university staff were positive about the development and execution of the new clinical education model. Collaborative development toward mutually beneficial goals strengthened the working relationship between the partners and offers a template for enhancing the partnership more broadly.

The combination telehealth and tele-supervision leveraged technological advancement and recognition of the changing face of clinical care provision. In this way, the clinical placement represents the forwardfacing reality of modern healthcare. Healthcare systems (particularly state systems) are wrestling with issues of access, increasing costs, infrastructure and integration of technology into usual care. Testing and evaluating new models of care and frequently updating ways of working to meet these challenges is likely to become 'core business' for clinicians moving forward.

\section{Challenges}

University academics needed to ensure that the placement model met professional learning objectives for Speech Pathology students, and quickly designed and provided support to clinical educators. This was challenging in the context of emerging guidelines regarding telehealth and tele-supervision. A new clinical placement model needs to align with course accreditation from the professional regulatory body. Ensuring alignment generated a large of volume of work for WIL staff with very tight deadlines due to the speed of changes brought on by the pandemic. This put considerable strain on the staff involved with an increased risk of overwork and burnout.

Clinical educators in the Speech Pathology department had to take on additional orientation and training for the new placement model. This training had to be undertaken alongside their clinical and administrative duties during an extremely busy and unpredictable period. As with the academic staff, this increased burden placed significant pressure on clinicians with the risks that this entailed (Bourne et al., 2020).

When a new model is delivered, expertise often lives within one or a small number of people coordinating delivery. If the person coordinating the new model moves on from the department, then continuity of delivery is impacted. In large health organisations, staff mobility is common, whether due to redeployment, secondment, retirement, advancement or changes to funding. This can be a particular barrier to sustainability of new placement models when working in smaller teams.

The introduction of new processes and care pathways that depended on technology brought inevitable technical issues. These included problems with availability and appropriateness of hardware and software, and technical capacity for some patients. Including students in this environment added complexity to working around such issues, compounded by the requirement to simultaneously meet student learning objectives. Matters of patient privacy also arose from the increased adoption of telehealth services which were complicated by inclusion of students in clinical encounters.

Moving part of the clinical education placement offsite changed the physical learning environment for students. A specific challenge was access to informal learning opportunities (Eraut, 2004), due to the fact that students spent less time in the usual clinical environment surrounded by peers and health professionals. Effective Speech Pathology services depend on professionals having the capacity and skills to work in team environments and connect at a personal level with colleagues and patients (Caballero et al., 2011). Students fed back concerns regarding the small amount of time spent onsite. This will be considered in future iterations of the model alongside recognition of the (sometimes limited) capacity within the clinical department. 


\section{Key learnings}

The key to the success of the clinical placement model lay in early and open-minded collaboration between the Speech Pathology department managers and clinicians and University WIL staff. The model worked to the extent that it did because both parties approached this collaboration in good faith to coproduce a mutually beneficial solution (Nisbet et al., 2020). This model has shown potential for innovative student placements combining telehealth and tele-supervision in speech pathology. The benefits to all parties suggest this model should be continued in the future, both in this setting and in other services looking to expand their capacity, client options and learning opportunities for students.

\section{ORCID}

Steven J. Kamper

Amabile B. Dario

Elizabeth Bourne

\author{
https://orcid.org/0000-0003-3012-5499 \\ https://orcid.org/0000-0002-4818-7017 \\ https://orcid.org/0000-0003-2501-193X
}

\section{References}

Australian Department of Health. (2020). National principles: Clinical education during the COVID-19 pandemic. Canberra. https://www.health.gov.au/sites/default/files/documents/2020/04/nationalprinciples-clinical-education-during-the-covid-19-pandemic.pdf

Bourne, E., McAllister, L., Kenny, B., \& Short, K. (2020). Speech pathologists' perceptions of the impact of student supervision. International Journal of Practice-Based Learning in Health and Social Care, 8(2), 1-15. https://doi.org/10.18552/ijpblhsc.v8i2.549

Caballero, C. L., Walker, A., \& Fuller-Tyszkiewicz, M. (2011). The work readiness scale (WRS): Developing a measure to assess work readiness in college graduates. Journal of Teaching and Learning for Graduate Employability, 2(2), 41-54. https://doi.org/10.21153/jtlge2011vol2no1art552

Chipchase, L., Hill, A., Dunwoodie, R., Allen, S., Kane, Y., Piper, K., \& Russell, T. (2014). Evaluating telesupervision as a support for clinical learning: An action research project. International Journal of Practice-based Learning in Health and Social Care, 2(2), 40-53. https://doi.org/10.11120/pblh.2014.00033

Eraut, M. (2004). Informal learning in the workplace. Studies in Continuing Education, 26(2), 247-273. https://doi.org/10.1080/158037042000225245

McAllister, L., Nagarajan, S., Scott, L., Smith, L., \& Thomson, K. (2018). Developing measures of placement quality in allied health, dentistry, medicine, and pharmacy. International Journal of Practice-based Learning in Health and Social Care, 6(2), 31-47. https://doi.org/10.18552/ijpblhsc.v6i2.493

Nagarajan, S., McAllister, L., McFarlane, L., Hall, M., Schmitz, C., Roots, R., Drynan, D., Avery, L., Murphy, S., \& Lam, M. (2016). Telesupervision benefits for placements: Allied health students' and supervisors' perceptions. International Journal of Practice-based Learning in Health and Social Care, 4(1), 16-27. https://doi.org/10.18552/ijpblhsc.v4i1.326

Nepean Blue Mountains Local Health District. (2017). Strategic Plan 2018-23. Penrith.

Nisbet, G., McAllister, S., Morris, C., \& Jennings, M. (2020). Moving beyond solutionism: Re-imagining placements through an activity systems lens. Medical Education, 55, 45-54. https://doi.org/10.1111/medu.14345

Rietdijk, R., Power, E., Attard, M., Heard, R., \& Togher, L. (2020a). A clinical trial investigating telehealth and in-person social communication skills training for people with traumatic brain injury: Participant-reported communication outcomes. Journal of Head Trauma Rehabilitation, 35(4), 241-253. https://doi.org/10.1097/htr.0000000000000554

Rietdijk, R., Power, E., Attard, M., Heard, R., \& Togher, L. (2020b). Improved conversation outcomes after social communication skills training for people with traumatic brain injury and their communication partners: A clinical trial investigating in-person and telehealth delivery. Journal of Speech Language and Hearing Research, 63(2), 615-632. https://doi.org/10.1044/2019_Jslhr$\underline{19-00076}$ 